\title{
Socio-pragmatic Transfer in Egyptian Refusals
}

\author{
By Alaa Darwish *
}

\begin{abstract}
Producing accurate and comprehensible language requires grammatical and syntactic knowledge; however, language accuracy does not ensure avoiding miscommunication which arises from the inappropriate use of speech acts. Thus, speech acts are among the prominent areas that have been investigated in the field of Inter-language pragmatics (ILP). Hence, the current study examines the realizations of the speech act of refusal by young adult Egyptian students in their L1 (Egyptian Arabic) and L2 (English). The study also explores the socio-pragmatic features of Egyptian refusals in terms of power and distance. 2270 cases of refusals were collected by means of a Discourse Completion Task (DCT) and field notes. The sample consists of 200 DCTs and 60 instances of refusals extracted from field notes collected by the researcher from natural observations. The data are analyzed according to an adaptation of the taxonomy of refusal strategies (RS) by Beebe et al. (1990). The findings reflect a great amount of positive pragmatic transfer as most of the participants' refusals are indirect refusals. The main strategies that are used include statements of explanations, statements of alternatives, and statements of regret. In addition, adjuncts to refusals such as gratitude and positive opinion are used in refusals to interlocutors of equal and higher power. Furthermore, the results reveal an amount of negative pragmatic transfer in the participants' L2 refusals. Finally, practical implications and future recommendations are suggested based on the given results.
\end{abstract}

Keywords: Communicative competence, Inter-language pragmatics, Pragmatic transfer, Refusals, Speech act theory

\section{Introduction}

Language comprehension requires knowledge of grammatical rules, phonology and syntax. Yet, language accuracy does not ensure avoiding miscommunication. That is, there are certain aspects of language use that are related to a community and its values. What makes certain expressions acceptable in one context may be judged as rude and unacceptable in another context. Thus, understanding the rules that govern how language is used in different communities, known as pragmatic competence, has gained importance in the field of second and foreign language acquisition and education.

Speech acts are among the prominent areas that have been investigated in the field of pragmatic competence as they are "the basic or minimal units of linguistic communication" (Searle 1969: 16). Speech acts were first introduced by Austin (1962) and Searle (1969) and after them a number of linguists have subsequently investigated speech acts to contribute to a better understanding of how linguistic behavior is realized and perceived across different languages and cultures. These linguists introduced a number of theories and concepts that formed the theoretical framework of the investigation of speech acts.

Hymes (1974) introduced the concept of communicative competence asserting the importance of a system of communication besides grammar essential to the use of language. A number of communicative competence models were

*MA TESOL, The American University in Cairo and Instructor, The German University in Cairo, Egypt. 
built based on Hymes' work, such as Canale and Swain (1980), Bachman and Palmer (1996, 2010). Bachman and Palmer's model (2010) offered a comprehensive description of the components of language knowledge, which they described as organizational knowledge and pragmatic knowledge. While organizational knowledge mainly focused on the knowledge of vocabulary, syntax, phonology, cohesion, and rhetorical or conversational organization, pragmatic knowledge focused on the communicative goals behind the use of the language. Thus, pragmatic knowledge comprises both functional knowledge and sociolinguistic knowledge. This and other recent models of communicative competence such as Celce-Murcia (2007) and Martínez-Flor and Usó-Juan (2006) emphasize the importance of pragmatic awareness alongside organizational awareness for effective communication. As the process of synthesizing both the linguistic and socio-cultural aspects of language to produce grammatical and appropriate utterance often prove challenging for language learners, many studies have aimed at either exploring the effect of instruction on developing pragmatic awareness or assessing students' pragmatic competence (e.g., Bu 2012, Garcia 2004, Gholami 2015, Jianda 2007, Maiz-Arévalo 2014, Matsugu 2014). Consequently, issues of pragmatic competence and pragmatic awareness are increasingly acknowledged as essential to language acquisition because failing to abide by the linguistic and cultural rules that govern language use may cause communication breakdowns known as pragmatic failure.

Thomas (1983) offered some explanations for pragmatic failure, which she described as either the lack of linguistic means to convey pragmatic knowledge or cross-cultural differences. For example, using an indirect request (e.g., It is cold in here) might be the norm in one language community but considered ambiguous in another community. Thomas clarified that socio-pragmatic failure is described as occurring due to lack of awareness of socio-cultural behaviors. When learners struggle with understanding appropriate socio-cultural behaviors due to lack of sufficient awareness of the L2 socio-pragmatic rules, they may rely on the rules governing L1 language use. This phenomenon is known as pragmatic transfer.

According to Beebe et al. (1990) pragmatic transfer occurs when the sociocultural aspects of L1 are used when producing L2; however, it is important to differentiate between positive and negative pragmatic transfer. While positive pragmatic transfer results from the similarities in the socio-cultural behavior of L1 and L2, negative pragmatic transfer results from the differences between L1 and L2 which may cause communication breakdown. Consequently, negative pragmatic transfer has been a major concern for ILP researchers such as BardoviHarlig et al. (2008), Beebe et al. (1990), Bella (2011), Chang (2009), CodinaEspurz (2013), and Félix-Brasdefer (2003).

Brown and Levinson (1987) introduced the politeness theory based on Goffman's (1967) notion of face where there are two types of face: positive and negative face. Negative face is the desire to be free of imposition and positive face is the desire to be liked by others. Accordingly, some speech acts such as apologies, refusals, and complaints represent a threat to another individual's face. These speech acts are known as face-threatening acts (FTA) because they can either threaten the face of the hearer or the speaker. For example, refusals, the 
focus of this study, threaten the requester's positive face as the refuser hinders the desire of the requester to have his/her actions unimpeded. Accordingly, strategies to mitigate threats to face can differ widely across languages and cultures. For example, while one language community may accept direct refusal, another community may consider it impolite or face-threatening, which might lead to miscommunication or pragmatic failure.

According to Brown and Levinson (1987), there are certain social aspects that should be analyzed during interactions when producing an FTA. In other words, the nature of an FTA such as a refusal or a request will be assessed by the speaker to choose the appropriate wording according to different socio-linguistic features. To assess a certain act there are three culture-sensitive factors that should be considered: the social distance between the interlocutors (D), the social power of one of the interlocutors over the other $(\mathrm{P})$, and the degree of imposition (I) of a certain action.

Based on Brown and Levinson's framework (1987), Scollon and Scollon (2001) classified face relationships into three politeness (or face) systems. According to this model of politeness, $\mathrm{P}$ is divided into a hierarchical politeness system: a super ordinate position $(+\mathrm{P})$, a subordinate position $(-\mathrm{P})$ and a position of equal social level with no interlocutor exerting power over the other $(=\mathrm{P})$. On the other hand, social distance is classified into two categories; a distant relationship $(+\mathrm{D})$ and a close relationship (-D).

To conclude, refusal is an important speech act that is worth investigating not only for being an inherently face-threatening act but also providing insight into the socio-pragmatic differences between L1 and L2 which are important for avoiding inter-cultural communication breakdowns among language learners.

\section{Literature Review}

The first line of research investigated speech acts within the same language and culture, known as intra-language studies. For example, Félix-Brasdefer (2006) investigated refusals of Mexican Spanish native speakers and reported a tendency to use direct refusals as an act of friendliness between equal status persons. On the other hand, Migdadi et al. (2010) focused on the communicative function of the Arabic religious formula/maafaallaah/divine will and its use in mitigating refusals. The second line of research analyzed refusals from a cross-cultural perspective, where the differences between the realizations of refusals in different cultures were observed. A large body of research investigated cross-cultural differences in producing refusal strategies. Among these studies are several that compared the East Asian culture to the American culture such as Kwon (2004) and Chang (2009). The findings of both studies suggest that East Asians use mitigating formulas more often than American English native speakers, which reveals that the East Asian refusals are more opaque and indefinite than English. In an Iranian context, there are various studies that compared Farsi speakers to native English speakers, among which are Allami and Naeimi (2011) and Ghazanfari et al. (2012) that compared Farsi and English refusals. While Allami and Naeimi (2011) 
explored the production of refusals realized by Iranian EFL learners of various proficiency levels by means of a Discourse Completion Task (DCT), Ghazanfari et al. (2012) focused their study on gender differences as well as cross-cultural differences. Results revealed that English speakers used fewer excuses than Farsi speakers. Strategies such as apology and lack of enthusiasm were used less frequently by Farsi speakers. Finally, a number of studies compared Arabic and English native speakers from a cross-cultural perspective (Hussien 1995, Huwari \& Al-Shboul 2015, Migdadi et al. 2010, Nelson et al. 1998, 2002, Stevens 1993). These studies compared the realization of refusal strategies in Arabic versus the production of native speakers of English. The findings of most of the studies that were conducted before Nelson et al. (1998) suggested that Arabic speakers preferred indirect communication and American English speakers preferred direct communication; however, in the study conducted by Nelson et al. (2002) Egyptians used more direct formulas in equal status situations. Although both groups employed similar reasons for refusing, they differed in the order of semantic formulas and the US refusals reported more frequent use of gratitude.

The third line of research investigates the effect of L1 on the nonnative speakers' acquisition, comprehension and realization of speech acts known as inter-language pragmatic studies (ILP). These studies investigated pragmatic transfer in the production of refusals by EFL learners in an attempt to suggest pedagogical implications for classroom instruction. For example, Stevens (1993) compared Arabic and English refusals via DCTs and concluded that Egyptian learners may not need to be explicitly taught refusal strategies as a result of the positive pragmatic transfer observed in the results. Al-Issa (2003), on the other hand, examined the transfer of Jordanian Arabic in the participants' L2 through a DCT and an interview. The results of the interviews suggest that the participants' cultural values may have had a significant effect on the amount of negative pragmatic transfer from their native Arabic. Allami and Naeimi (2011) and Codina-Espurz (2013) investigated the effect of proficiency on the pragmatic development in realizing refusal strategies. Surprisingly, the results showed a considerable amount of negative pragmatic transfer especially in the higher proficiency levels. Both studies in Iran and Spain asserted the importance of pragmatic awareness in addition to grammatical awareness.

From the brief review above it appears that refusal strategies in learners' L2 do not just vary in terms of the content of the semantic formulae due to cultural differences, but that there is also a phenomenon of pragmatic transfer from L1 in most language contexts. Among the research on Arabic speakers is Stevens (1993), who compared English and Arabic refusals. The instructions of the DCT were administered in Modern Standard Arabic (MSA), which may have affected the naturalness of the responses gathered even if they were asked to answer in Egyptian Colloquial Arabic (ECA) because using standard Arabic would make certain situations more formal (i.e., situations of equal power) which might affect the level of formality of the responses. Although Hussein (1995) studied the sociolinguistic patterns of native Arabic speakers based on natural observations, the refusals were reported in MSA which is also not the same semantic or syntactic formulae used in their natural spoken dialect. Studies that focused on 
Egyptian Arabic refusals were only conducted by Nelson et al. (1998, 2002). While Nelson et al. (1998) compared the Egyptian refusal strategies to the strategies used by native English speakers, Nelson et al. (2002) focused on the use of direct versus indirect refusal strategies across Egyptians and Americans; however, to the best of the researcher's knowledge, only one study conducted in Iran by Shishavan and Sharifian (2013) examined the production of refusal strategies from the same group in their native language and their second language to analyze the amount of pragmatic transfer. Hence, conducting such a study in an Egyptian context would bridge the gap in this area of intra-linguistic research. In other words, the results of this study may help in clarifying whether there is a need for classroom instruction on pragma-linguistic issues due to the fact that the previous literature has come to different conclusions on this topic. To illustrate, while Stevens (1993) suggested that there was no need for classroom pragmatic instructions based on the findings of his study that reported positive pragmatic transfer, Al-Issa (2003) suggested the importance of teaching the socio-pragmatic rules of L2.

\section{Research Questions}

The aim of the study is to explore the speech act of refusal realized by young adult learners in both their L1 and L2 through answering the following research questions:

1. What are the strategies used for refusals by Egyptian students in private universities using English as their L2?

2. What are the strategies used for refusals by the same students in private universities using their native Egyptian Arabic?

3. What are the aspects of pragmatic transfer produced by the students in L2?

\section{Methodology}

\section{Participants}

The total number of respondents to the DCT was 100 participants (36 males and 64 females) ranging in age from 17 to 20 years old. All respondents were intermediate undergraduate students enrolled in private Egyptian universities. Students had not previously traveled to an English-speaking country.

Field notes were gathered by the researcher during the same period of administering the DCTs from the same convenient sample in addition to gathering the instances of refusals between the students and their instructors, whose ages varied from 26 to 29 years old. While the DCT data were collected from students who accepted to fill out the DCT, field notes observations were collected from students who refused to fill out the DCT in addition to other exchanges that included refusals whether inside or outside the class. As a result, 60 instances of 
ECA refusals were collected by natural observation: 40 of these came from females and 20 of these from males. Exchanges between the students and their teachers or their peers were recorded on a written form designed by the researcher. This form included the interlocutors' gender, the power and the distance between the requester and the refuser. Moreover, participants' use of body language, gestures and facial expressions were also recorded when pertinent.

\section{Instrument}

The main data collection method of this research is the DCT, which is believed to be an adequate instrument for this study based on Kasper's (2000) argument that a DCT is an effective means of data collection when the purpose of the study is to "inform about speakers' pragma-linguistic knowledge of the strategies and linguistic forms by which communicative acts can be implemented, and about their socio-pragmatic knowledge of the context factors under which particular strategic and linguistic choices are appropriate" (Kasper 2000: 329). Moreover, DCTs have their own advantages in pragmatic research because they can be administered to a large number of participants, no transcription is needed, and they are easy to assess. DCTs are controlled elicitation methods that provide researchers with a means of controlling various sociolinguistic variables such as the power relation and the social distance between participants and establishing the statistical data which are significant intra-linguistically as well as across-culturally. Since the goal of the present study was to scrutinize the participants' use of refusal strategies under in specific situations, a DCT was chosen as the most appropriate for data collection. Furthermore, the data of the natural observations were compared to the data of the DCT to check the naturalness of the data collected by the DCT bearing in mind the limitations of field observations which are the limited quantity and the difficulty of recording accurately in writing.

The DCT developed for this study was guided by the situations in the DCT developed by Beebe et al. (1990). It was previously that was used and adapted in various cross-cultural and ILP studies (e.g., Allami \& Naeimi 2011, Chang 2009, Kwon 2004). For this study, two DCTs were developed: one in English and the other in ECA. Both DCTs consisted of six situations (three offers and three requests) and an initiating act to stimulate the participants' refusal. The adaptations for this study focused on two aspects: First, the hypothetical situations in a workplace environment were changed to situations suitable for university students' everyday life. For example, the vase which was broken by the cleaning lady in situation 2 in the original DCT was changed to be a laptop in the English DCT and a car headlight in the Arabic DCT. Second, the situations in the Arabic DCT were developed in different contexts from the English DCT; however, I and P were maintained. For example, the equal power was a cousin in the L2 and a close friend in L1 to maintain the same social distance. Moreover, the higher social power was presented as a professor requesting a task from a student and the lower power was presented either as a cleaner in L2 or a doorman in L1. The context of the situations was modified to guarantee that the students would not translate from L1 to L2 or vice versa. 
The participants were encouraged to write the responses as naturally as possible. Consequently, they were permitted to write either in ECA or Arabizi (informal orthography of Arabic language using Latin letters and Arabic numerals that was originally used in texting) in the ECA situations. They were also allowed to write what they would actually do if their responses were not verbal or if they wanted to accompany the response with emoticons (representations of facial expressions used in texting such as wink or frown). These measures allowed the participants to respond as naturally as possible as these techniques were suitable for their age group.

The second data collection method was field notes, which is considered the most reliable data collection method in the field of ILP and speech act research (Chamani and Zareipur 2010, Kasper 2000, Wolfson and Manes 1980) as it reflects language as it is actually used in real life situations. Moreover, Wolfson and Manes' (1980) pioneering strategy in collecting ethnographic field notes was followed by a number of researchers who collected ethnographic data on different speech acts such as apologies, refusals, compliments, and compliment responses (i.e., Chamani and Zareipur 2010, Izadi and Zilaie 2015, Shishavan 2016, Mostafa 2015).

\section{Procedures}

The DCT instructions were presented orally and the first situation in L1 and L2 were acted out loud by the researcher before filling the written DCT. The reason behind this measure was to ensure the clarity of the instructions and following the planned flow of the experiment. Second, explaining the instructions and acting out the situations orally by the researcher through controlling voice intonation and variation in the initiating speech act helped in maintaining the naturalness of the students' responses to the initiating act. This measure together with asking the students to write as naturally as possible using Arabizi, emoticons or even explaining what they would really do in those situations made the DCT the closest it could have been to natural language production.

As for the field observations, the researcher recorded the data of the students who refused to fill out the DCT on the field observation form. Second, students were asked if they had ever faced a similar situation to those in the DCT to ensure the validity of the situations. Students confirmed facing similar situations on different occasions; however, the most common situations were mainly the situation of the maid and the situation of asking the professor's feedback (see Appendix A). Other field notes were collected on various occasions as in classrooms, in the office listening to exchanges between instructors and their students during office hours or exchanges between students in the university bus. By the end of this process, 60 instances of refusal were collected to be analyzed.

The data were analyzed qualitatively and quantitatively according to the taxonomy developed by Beebe et al. (1990) on which refusal strategies are divided into direct, indirect strategies and adjuncts to refusals (see Appendix B). Qualitatively, the responses of the DCTs and the refusal strategies collected from field notes were analyzed by the researcher and a second rater (a fellow M.A. 
student of linguistics) according to an adaptation of the taxonomy developed by Beebe et al. (1990). As for the quantitative data, SPSS was used for both the descriptive statistics and the statistical significance of the amount of transfer using chi-square.

\section{Results}

For the main aim of the study, which is to explore the refusals produced by Egyptian young adults in L1 and L2, a total of 2,270 instances of refusals were collected from 1,230 tokens: 1,054 instances from the English DCT, 1,147 instances from the Arabic DCT and 69 instances from the field notes. Instances might contain more than one refusal strategy (RS) which were analyzed separately.

The data in Table 1 illustrate that the most frequently used RS in both L1 and L2 are indirect strategies or combinations of indirect and adjuncts, especially when refusing the offers of a higher or an equal social status person. The nature of the initiating act whether a request or an offer is displayed together with the social status of the requester or the person who presents the offer. The sixth and seventh columns reflect the strategies used by the refuser of each situation as divided into direct refusals, indirect refusals, and adjunct refusals for both L1 and L2 responses.

Table1. Frequencies of RS and Status in the English and Arabic DCTs

\begin{tabular}{|c|c|c|c|c|c|c|}
\hline Situation & Situation & $\begin{array}{c}\text { Initiating } \\
\text { act }\end{array}$ & $\begin{array}{l}\text { Social } \\
\text { status }\end{array}$ & $\begin{array}{l}\text { Refusal } \\
\text { strategy }\end{array}$ & \multicolumn{2}{|c|}{ Frequency } \\
\hline$L 2$ & $L 1$ & & & & $L 2$ & $L 1$ \\
\hline \multirow{3}{*}{1} & \multirow{3}{*}{2} & \multirow{3}{*}{ Request } & \multirow{3}{*}{$=\mathrm{P}$} & Direct & 1 & 0 \\
\hline & & & & Indirect & 191 & 214 \\
\hline & & & & Adjunct & 0 & 5 \\
\hline \multirow{3}{*}{2} & \multirow{3}{*}{1} & \multirow{3}{*}{ Offer } & \multirow{3}{*}{$-\mathrm{P}$} & Direct & 1 & 0 \\
\hline & & & & Indirect & 113 & 129 \\
\hline & & & & Adjunct & 7 & 5 \\
\hline \multirow{3}{*}{3} & \multirow{3}{*}{6} & \multirow{3}{*}{ Request } & \multirow{3}{*}{$-\mathrm{P}$} & Direct & 1 & 1 \\
\hline & & & & Indirect & 145 & 144 \\
\hline & & & & Adjunct & 3 & 1 \\
\hline \multirow{3}{*}{4} & \multirow{3}{*}{3} & \multirow{3}{*}{ Offer } & \multirow{3}{*}{$=\mathrm{P}$} & Direct & 0 & 0 \\
\hline & & & & Indirect & 157 & 149 \\
\hline & & & & Adjunct & 38 & 42 \\
\hline \multirow{3}{*}{5} & \multirow{3}{*}{5} & \multirow{3}{*}{ Offer } & \multirow{3}{*}{$+\mathrm{P}$} & Direct & 0 & 0 \\
\hline & & & & Indirect & 194 & 184 \\
\hline & & & & Adjunct & 30 & 28 \\
\hline \multirow{3}{*}{6} & \multirow{3}{*}{4} & \multirow{3}{*}{ Request } & \multirow{3}{*}{$+\mathrm{P}$} & Direct & 1 & 0 \\
\hline & & & & Indirect & 180 & 240 \\
\hline & & & & Adjunct & 0 & 5 \\
\hline
\end{tabular}

The findings are explored from the socio-pragmatic perspective of power. These refusals are subdivided into refusals of requests and refusals of offers. While 
Table 1 shows the number of direct, indirect and adjuncts to refusals produced by the participants in each situation, Tables 2 and 3 provide a comprehensive display of the semantic formulas of RS used by the participants in percentiles and the total number of each RS realized. The semantic formulas were coded based on Beebe et al.'s (1990) taxonomy (see Appendix B). The majority of refusals to both offers and requests, whether in L1 or L2, took the form of indirect refusals using the strategy of explanation. The only significant exception appeared in refusing the offer of lower power in L1, where no records of explanation were displayed and only $1.7 \%$ in L2.

Table 2. The Semantic Content of RS in the English and Arabic DCT

\begin{tabular}{|c|c|c|c|c|c|c|c|c|c|c|c|c|}
\hline \multirow{3}{*}{$\begin{array}{l}\text { Semantic Formula } \\
\% \\
\end{array}$} & \multicolumn{6}{|c|}{ Requests } & \multicolumn{6}{|c|}{ Offers } \\
\hline & \multicolumn{2}{|c|}{ Higher } & \multicolumn{2}{|c|}{ Equal } & \multicolumn{2}{|c|}{ Lower } & \multicolumn{2}{|c|}{ Higher } & \multicolumn{2}{|c|}{ Equal } & \multicolumn{2}{|c|}{ Lower } \\
\hline & $L 2$ & $L 1$ & $L 2$ & L1 & $L 2$ & L1 & L2 & $L 1$ & L2 & L1 & L2 & $L 1$ \\
\hline Principle & & & 1 & 0.5 & & & & & & & & 1.5 \\
\hline Philo & & & & & & 2.7 & & 0.5 & & & 3.3 & 17.9 \\
\hline Crit & & & 10.9 & & 7.4 & 24.7 & & 0.5 & & & 27.3 & 9 \\
\hline Hook & & & & & & & & & & & 52.1 & 64.9 \\
\hline PHD & 0.6 & & 0.5 & & & & & & & & & 0.7 \\
\hline Rep & 0.6 & 1.2 & & & & & \begin{tabular}{|l|}
0.9 \\
\end{tabular} & & 1 & 2.1 & 2.5 & 2.2 \\
\hline Reg & 28.7 & 31.4 & 37 & 28.3 & 20.1 & 16.4 & 26.3 & 25.5 & 19.5 & 15.2 & 0.8 & \\
\hline Wish & 0.6 & 0.8 & 0.5 & 0.5 & & 2.1 & 4.5 & 2.8 & & 0.5 & & \\
\hline Exp & 41.4 & 37.6 & 32.3 & 35.2 & 45.02 & 30.8 & 42.9 & 42.9 & 49.2 & 47.6 & 1.7 & \\
\hline Alt & 18.8 & 18.8 & 14.6 & 27.4 & 13.4 & 12.3 & 8 & 9 & \begin{tabular}{|l|}
3.1 \\
\end{tabular} & 5.2 & 3.3 & \\
\hline Cond & 3.3 & 2.9 & 0.5 & 2.7 & 4.7 & 4.1 & \begin{tabular}{|l|}
0.9 \\
\end{tabular} & 2.4 & 0.5 & & & \\
\hline Promise & & 0.8 & & 0.5 & & & & 0.5 & & & & \\
\hline Pstp & 5 & 3.7 & & 2.3 & 2 & 1.4 & 1.8 & 1.4 & 0.5 & 3.1 & & \\
\hline $\mathrm{NC}$ & 0.6 & 0.8 & 0.5 & 0.5 & & \begin{tabular}{|l|}
0.7 \\
\end{tabular} & \begin{tabular}{|l|}
0.4 \\
\end{tabular} & 0.5 & & & & \\
\hline TS & & & & & 2.7 & \begin{tabular}{|l|}
0.7 \\
\end{tabular} & & & & 0.5 & 1.7 & \\
\hline Joke & & & & & & \begin{tabular}{|l|}
1.4 \\
\end{tabular} & & & & 3.7 & 0.8 & \\
\hline PO & & 1.2 & & & & & 5.8 & 4.2 & 2.6 & 5.2 & & \\
\hline RH & & & 1.6 & & & & \begin{tabular}{|l|}
0.9 \\
\end{tabular} & 0.5 & \begin{tabular}{|l|}
4.1 \\
\end{tabular} & & & \\
\hline IR & & & & & 1.3 & & & 0.5 & & & & \\
\hline SD & & & & & 0.7 & & & & & & & \\
\hline Grat & & & & & 2 & & 6.7 & 8 & 17.9 & 16.2 & 5 & 3.7 \\
\hline Emp & & & & & & \begin{tabular}{|l|}
0.7 \\
\end{tabular} & & 0.5 & 0.5 & & & \\
\hline Filler & & 0.8 & & 2.3 & & & \begin{tabular}{|l|}
0.9 \\
\end{tabular} & 0.5 & 1 & 0.5 & 0.8 & \\
\hline Direct & 0.6 & & 0.5 & & 0.7 & \begin{tabular}{|l|}
0.7 \\
\end{tabular} & & & & & 0.8 & \\
\hline Total $(\mathrm{N}=)$ & 181 & 245 & 192 & 219 & 149 & \begin{tabular}{|l|}
146 \\
\end{tabular} & 224 & 212 & 195 & 191 & 121 & 135 \\
\hline
\end{tabular}

\section{Refusing Offers}

Most of the participants produced the largest number of instances of RS while refusing the offer of a higher social status (212 RS in L1 and $224 \mathrm{RS}$ in L2). For example, participants only used seven types of RS to refuse the offer of a lower power, and 11 types of RS to refuse the offer of an equal power. On the other hand, most of the responses were realized as a combination of two or three RS (i.e., gratitude/positive opinion and explanation or regret, explanation and 
alternative.); for example, "Sorry professor, but I already planned with my friends." from the English DCT and /Pana Pasef ya duktur, Pana eftarakt fkaza klab

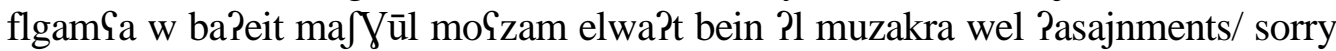
professor, but I'm already a member in many clubs and I'm busy most of the time studying and finishing my assignments. Both of these sample responses in English and in Arabic used a combination of statement of regret and an explanation.

Table 3. Frequencies of RS in Field Notes

\begin{tabular}{|l|c|c|c|c|c|c|}
\hline \multirow{2}{*}{ Semantic Formulas } & \multicolumn{2}{|c|}{ Higher } & \multicolumn{2}{c|}{ Equal } & \multicolumn{2}{c|}{ Lower } \\
\cline { 2 - 7 } & $N$ & $\%$ & $N$ & $\%$ & $N$ & $\%$ \\
\hline Philo & 1 & 2 & 1 & 20 & 1 & 4.76 \\
\hline TS & 1 & 2 & 1 & 20 & 1 & 4.76 \\
\hline Crit & 0 & 0 & 0 & 0 & 4 & 19.04 \\
\hline Reg & 0 & 0 & 0 & 0 & 1 & 4.76 \\
\hline Exp & 18 & 37.5 & 2 & 40 & 2 & 9.52 \\
\hline Alt & 4 & 8.3 & 0 & 0 & 1 & 4.76 \\
\hline Cond & 0 & 0 & 0 & 0 & 1 & 4.76 \\
\hline RH & 1 & 2 & 0 & 0 & 0 & 0 \\
\hline Pstp & 16 & 33.3 & 0 & 0 & 0 & 0 \\
\hline Joke & 0 & 0 & 0 & 0 & 1 & 4.76 \\
\hline PHD & 3 & 6.25 & 0 & 0 & 4 & 19.04 \\
\hline Do nothing & 4 & 3.8 & 0 & 0 & 0 & 0 \\
\hline NC & 0 & 0 & 0 & 0 & 0 & 0 \\
\hline Filler & 0 & 0 & 0 & 0 & 0 & 0 \\
\hline PO & 0 & 0 & 0 & 0 & 1 & 4.76 \\
\hline Grat & 0 & 0 & 2 & 40 & 2 & 9.52 \\
\hline FN & 0 & 0 & 0 & 0 & 2 & 9.52 \\
\hline
\end{tabular}

On refusing the offer of an equal power, explanations were also the most frequently used strategy. This was also often combined with an adjunct to refusal such as gratitude or combined with a statement of regret. It appears from both the data and the comments collected from field notes that refusing food offers is considered highly face-threatening according to this age group. More than $15 \%$ of the students commented on this situation wondering why they would say no to food. While others commented that they could take the food and never eat it so that they would not embarrass their interlocutor.

Finally, the most frequent strategy used to refuse the offer of the lower social power was letting the interlocutor off the hook in both L1 and L2. This situation is especially interesting from a socio-pragmatic point of view as some of the formulas used by the interlocutors reflected socio-pragmatic aspects related to the Egyptian society such as the evil eye, using statements of philosophy and invoking the name of God. As for the responses related to refusing the offer of a lower status in L2, participants had the same initial preference which is letting the interlocutor off the hook. On the other hand, the second preference changed to an extent, where the frequency of using criticism increased and using the statement of philosophy was also minimized to $3.3 \%$ while it was $17.9 \%$ in L1. 
The results show that the participants used more RS. They were also more likely to combine two or more RS when refusing an offer from an individual of higher power. This is likely explained by participants' fear of offending interlocutors perceived to be of higher status. Second, there is a general tendency among participants not to refuse food offers for the same reason; however, when they refused, they mitigated the refusals through the use of a combination of adjuncts to refusals and explanations. Finally, refusing the offer of a lower status person which implied an apology in it was different to an extent. More explicitly, while most of the participants refused the money offer, other participants did not accept the apology implied in the offer and thus produced a refusal which is facethreatening even though it is an indirect refusal (i.e.; criticizing or attacking the interlocutor).

\section{Refusing Requests}

On refusing the request of a higher power, participants' preference was to either use a combination of a statement of regret and an explanation or use an explanation and a statement of alternative in both L1 and L2. Some used three strategies for the same act (regret, explanation and alternative). The highest frequency of refusal strategies used by participants refusing the request of a higher power in field notes conformed with the DCT, which is explanation or a combination of explanation and alternative. The results varied in the second preference which was postponement in the field notes. The reason behind this difference is probably the nature of the request itself and the distance between the interlocutors. While the distance between the student and the professor was familiar (-D) in the DCT, the distance between the teacher and the students was $(+\mathrm{D})$ as it was their first time to meet on the day they were asked to fill the DCT. For example, one student refused filling the DCT saying that he had to leave but that he could come and fill it at any other time (explanation and postponement). It was also noted in the field notes that resorting to avoidance by being silent and doing nothing occurred more than once. One student even mentioned while completing the DCT that sometimes she did not want to accept a certain request or an offer such as the situation she was refusing in the DCT but she did not know what to say, so she would either remain silent or accepted for fear of being rude.

On refusing the request of an equal power, results varied between L1 and L2 in the second preference which was the statement of regret combined with an explanation or an explanation and an alternative. While some strategies appeared only in the production of the students in L2 which is criticism (21\%) and requesting help (3\%), others appeared in their production in L1 (filler and postponement).

The participants used explanation on refusing a lower status person's request in both L1 and L2. Their second preference was using criticism in L1 (24.7\%) while this was their fourth preference $(7.4 \%)$ in L2. On the other hand, criticism came as the first preference in field notes. It is important to note that the distance between the interlocutors may have been the reason for this difference as well as the amount of imposition on the refuser. For example, in one of the field notes 
recorded by the researcher one of the students' requests was to leave early and that was the fourth time she asked to leave early which increased the imposition on the respondent (teacher). Also, one of the teachers had a comment on the issue of distance saying that it is the nature of the relation between the teacher and the students that makes the difference. In other words, this rapport between the teacher and the students makes a certain comment or act accepted from one teacher who is popular with the students and the same comment or act is not accepted from another teacher who is distant from the students. Another comment was that sometimes being too indirect can be vague for some students and they needed to be as clear as possible.

\section{Aspects of Transfer in Egyptian Refusals}

Strategies used by the participants while refusing offers were very similar which may suggest a positive pragmatic transfer as the difference between the percentages each strategy used in L1 and L2 does not exceed 4\%. A chi-square analysis showed that there were no significant differences between L1 and L2 in the strategies used by participants refusing the offer of the higher and equal power $\left(\chi^{2}=11.008, p=0.809\right)$ and $\left(\chi^{2}=11.672, p=0.472\right)$. Finally, the clearest difference between the participants' responses in L1 and L2 was mainly related to the use of statement of philosophy in L1, which was minimized in their L2 production. This may suggest students' socio-pragmatic awareness as they did not transfer cultural specific expressions. This is supported by the statistical significance as refusing lower power's offer showed high significance $\left(\chi^{2}=42.464, \mathrm{p}=0.000\right)$.

On comparing the refusals to requests, the differences between the strategies realized by the participants in L1 and L2 varied more than the data rendered by offers as the difference between the frequency of some strategies reached $20 \%$ in cases such as regret, explanation and using statement of alternative. The strategies used on refusing the request of equal and lower power showed significant differences $\left(\chi^{2}=53.225, \mathrm{p}=0.000, \chi^{2}=39.442, \mathrm{p}=0.001\right)$.

Although comparing the semantic formulae used by the participants showed more similarity than difference between the participants' realization of refusal in L1 and L2, the qualitative analysis of the data showed a degree of negative pragmatic transfer. It appeared from the data that the main aspects that were found in L1 refusals were the statement of philosophy, the concept of the evil eye and religious formulas. While some of these religious formulas included invoking the name of God such as /qaddar allaah wama Jaa? faSal/ God predetermined and $\mathrm{He}$ did what He intended, others did not, i.e.; /jalla, qad`aa? wa qadar/ Well, it was meant to be. These previously mentioned examples not only express the religious socio-cultural background, but are also considered statements of philosophy together with other expressions such as /maba?bal $\int$ el Sawad/ I do not accept compensation. On the other hand, the concept of the evil eye was clear in expressions such as /xadet e $\int \mathrm{ar} \mathrm{w}$ rahet/ it took the evil eye with it and /gat fl hadiid/ the evil eye was drawn to the car instead of humans; however, these expressions that implied the concept of the evil eye were found in only 12 cases. 
While the data reported very few cases of transfer related to invoking the name of God or to the concept of evil eye, some responses implied negative sociopragmatic transfer, such as "May God compensate me, but please be careful next time" or "I'm not sad, it's their destiny" in response to offering to fix the laptop in situation 2.

\section{Discussion}

\section{Strategies Used for Refusals by ESL Egyptian Students in their L2}

The results show that the targeted population has a tendency to mitigate refusals by means of using indirect refusals or combinations of adjunct and indirect refusals. On examining these indirect refusals, it appeared that in most cases the highest preference is to the use of explanation, statement of alternative, statement of regret, and gratitude. Letting the interlocutor off the hook was a strategy that was extensively used only in the condition of the refusal to an offer that implied an apology. While in some cultures such as Asian cultures as indicated by Chang (2009) and Beebe et al. (1990) using direct refusals might threaten the face of the interlocutor and thus, it is avoided. Egyptians seems to intend this face-threat by using criticism whether to refuse a request or an offer of high imposition with an equal power or with a lower power. In other cases, the face threat is mitigated by use of indirect and adjunct refusals or by completely avoiding the refusal. This avoidance was mainly reported in the field notes as students kept silent and did nothing or left the room when they refused to fill out the DCT.

On comparing the results of the English DCT to studies that have investigated the production of English native speakers (NS), the results of the study in hand complies with Nelson et al. (1998) that the Egyptian communication style is indirect and the study also agrees with Nelson et al. (1998) and Stevens (1993) that Egyptians and Americans use the same strategies for refusals; however, there was a difference related to the refusals of equal power as in this study equal power rarely used direct strategies, whereas according to Nelson et al. (1998) a majority of equal power Egyptians used direct strategies in Arabic (70\%). Moreover, direct refusals were also recorded as the highest preference among American English NS according to Kwon (2004) as both refusing higher and equal social power requests were realized as direct refusals (more than $80 \%$ ).

The results also demonstrate that the distance between the interlocutors affected the type of strategy used. For example, on refusing a higher status, students' responses varied according to the degree of familiarity with the teacher. In the DCT, the relation between the teacher and the student was a familiar relation and thus the refusal was softened by one or two strategies. While it was observed that the less the familiarity between the teacher and the student the less the students preferred to talk. An example to that was clear from the field notes as the students who refused to fill out the DCT either left the room silently, or just put the paper aside and did nothing. When the researcher encouraged them to 
participate, their answers were very short, for example, such as / Gandena muzakra/ we have to study; which is rather abrupt and might seem offensive.

\section{Strategies Used for Refusals in Native Egyptian Arabic}

Similar to responses to the English DCT, the participants' mainly used indirect refusals. While some only used one indirect strategy, most of the participants used more than one strategy to soften their refusals. Another similarity was the semantic content of the refusals as most of the indirect strategies used were mainly explanations, statement of alternative, regret and gratitude. Direct strategies were rarely used and when they were used while refusing equal or lower status they did not aim at offending the interlocutor but being clear in case of refusing a lower status person. When the face threat was intended, Egyptian speakers, according to the data reported, usually used criticism and sometimes combined it with sarcasm.

\section{Socio-Pragmatic Transfer in Egyptian Refusals}

While results showed very little discrepancy between the strategies used by the participants in L1 and L2, Arabic refusals reflected some socio-pragmatic aspects related to the Egyptian society. These included, for example, the religious background and the belief in fate, the concept of the evil eye, the frequent use of statement of philosophy, and sometimes joking for mitigation. While most of the participants confined these expressions to the responses in L1, when they were used in L2 they usually represented instances of negative pragmatic transfer.

When students used statement of philosophy in their L1, sometimes it implied invoking the name of God such as /Yafa allaah Samma salaf/ God forgives what happened or /qaddar allaah w ma shaa? faSal/ God predetermined and He did what He wanted. On the other hand, statement of philosophy was minimized in L2 and when it was used it reflected positive pragmatic transfer such as "it happens to the best of us" or "accidents happen". While this strategy showed pragmatic awareness as students managed to transfer them correctly into the L2, other expressions related to fate showed a level of negative pragmatic transfer, for example, "it's their destiny" in situation 2. Students could have used other expressions like "it was meant to be".

Other transferred expressions were caused by the students' attempts to use witty comments to mitigate refusals, such as "I'm not on good terms with lamb". This expression was vague even to the researcher until reading the Arabic equivalent which is /ana welPerfa $\mathrm{m} \int \mathrm{sohab} /$ which literally meant: I'm not cinnamon's friend. Despite the fact that the data did not reflect a high percentage of joking as a strategy to soften refusals, joking is considered as part of Egyptians' everyday language. The low percentage of joking might be the result of the nature of the refusal as a face-threatening act. Joking in such conditions might be understood as sarcasm, which might offend the interlocutor. On the other hand, sarcasm, where the face threat was intended, appeared clear in the participants' responses, such as "don't worry, I'll find someone like you" in order to communicate the firing of the cleaner. 


\section{Conclusion}

Overall, the results suggest a high level positive pragmatic transfer. Among the aspects that were found in common are the use of indirect strategies especially explanations, alternatives and adjuncts to refusals. Second, Arabic refusals reflected some socio-cultural aspects related to the Egyptian society, such as the tendency to use non-verbal refusals with distant relations and the extensive use of statement of philosophy and invoking the name of God. Some other aspects were less frequent; however, they occurred in the data, such as the belief in the evil eye and using jokes for either mitigating refusals or criticism. Finally, although the data reported a high level of positive pragmatic transfer, some aspects of negative pragmatic transfer were present in the L2 refusals.

This research suggests that the speech act of refusal should be taught explicitly to minimize the probability of pragmatic failure. As shown from the results of the field notes and the English DCT, when some students wanted to refuse the offer or the request, they either kept silent or their answers were abrupt and sounded face-threatening even in their L1. While most of the studies in ILP in the Arabic context have been descriptive studies, instruction-based studies in other contexts support the importance of targeted instruction of appropriate refusal strategies (e.g., Bu 2012, Garcia 2004, Gholami 2015, Maiz-Arévalo 2014, Soler \& Pitarch 2010, Usó-Juan 2013). From a different angle, refusals in Arabic might sound challenging to teach because of the socio-cultural aspects that appear in the context of the refusals. The learners of Arabic as Foreign Language should be taught that using statements of philosophy and figurative language is part of the Egyptian everyday language; this echoes the recommendations made by Morkus (2009). Upon understanding this figurative language and knowing how to use it, not only pragmatic failure will be minimized, but also ECA refusals realized by L2 learners would sound more natural and closer to native Egyptian refusals.

\section{Acknowledgments}

This paper is based on sections from my M.A. thesis; thus, I would like to express my sincere gratitude to my readers and professors: Dr. Marilyn Plumlee, Dr. Amira Agameya and Dr. Reem Bassiouney for their enlightening comments and suggestions. I would also like to thank my raters Ms. Sarah Magdy and Ms. Nermin Hosny for their valued time and effort. Finally, I am especially grateful to the two anonymous reviewers for their critical comments and suggestions on an earlier version of this manuscript and Ms. Alyssa Young for editing and proofreading the final version of the article. 


\section{References}

Al-Issa A (2003) Sociocultural transfer in L2 speech behaviors: Evidence and motivating factors. International Journal of Intercultural Relations 27(5): 581-601.

Allami H, Naeimi A (2011) A cross-linguistic study of refusals: An analysis of pragmatic competence development in Iranian EFL learners. Journal of Pragmatics 43(1): 385406.

Austin JL (1962) How to do things with words. Oxford, England: Calderon Press.

Bachman LF, Palmer AS (1996). Language testing in practice: Designing and developing useful language tests. Oxford, England: Oxford University Press.

Bachman LF, Palmer A (2010). Language assessment in practice: Developing language assessments and justifying their use in the real world. Oxford, England: Oxford University Press.

Bardovi-Harlig K, Rose M, Nickels EL (2008) The use of conventional expressions of thanking, apologizing, and refusing. In M Bowles, R Foote, S Perpiñán, R Bhatt (Eds.), Selected Proceedings of the 2007 Second Language Research Forum, Cascadilla Proceedings Project (pp. 113-130). Somerville, MA.

Beebe LM, Takahashi T, Uliss-Weltz R (1990) Pragmatic transfer in ESL refusals. In R Scarcella, E Andersen, SD Krashen (Eds.), On the development of communicative competence in a second language (pp. 55-73). New York, NY: Newbury House.

Bella S (2011) Mitigation and politeness in Greek invitation refusals: Effects of length of residence in the target community and intensity of interaction on non-native speakers' performance. Journal of Pragmatics 43(6): 1718-1740.

Brown P, Levinson SC (1987) Politeness: Some universals in language usage. Cambridge, England: Cambridge University Press.

$\mathrm{Bu}$ J (2012) A study of the effects of explicit and implicit teachings on developing Chinese EFL learners' pragmatic competence. International Journal of Language Studies 6(3): 57-80.

Canale M, Swain M (1980). Theoretical bases of communicative approaches to second language teaching and testing. Applied Linguistics 1: 1- 47.

Celce-Murcia M (2007) Rethinking the role of communicative competence in language teaching. In E Alcón, MP Safont (Eds.), Intercultural language use and language learning (pp. 41-57). Dordrecht, Netherlands: Springer.

Chamani F, Zareipur P (2010) A cross-cultural study of apologies in British English and Persian. Concentric: Studies in Linguistics 36(1): 133-153.

Chang YF (2009) How to say no: An analysis of cross-cultural difference and pragmatic transfer. Language Sciences 31(4): 477-493.

Codina-Espurz V (2013) The role of proficiency in the production of refusals in English in an instructed context. Utrecht Studies in Language and Communication 25: 121-146.

Félix-Brasdefer JC (2003) Declining an invitation: A cross-cultural study of pragmatic strategies in American English and Latin American Spanish. Multilingua 22(3): 225256.

Félix-Brasdefer JC (2006) Linguistic politeness in Mexico: Refusal strategies among male speakers of Mexican Spanish. Journal of Pragmatics 38(12): 2158-2187.

Garcia P (2004) Developmental differences in speech act recognition: A pragmatic awareness study. Language Awareness 13(2): 96-115.

Ghazanfari M, Bonyadi A, Malekzadeh S (2012) Investigating cross-linguistic differences in refusal speech act among native Persian and English speakers. International Journal of Research Studies in Language Learning 2(4): 49-43.

Gholami J (2015) Is there room for pragmatic knowledge in English books in Iranian high schools?. English Language Teaching 8(4): 39-51. 
Goffman E (1967) Interactional ritual. Garden City, NY: Anchor.

Hussein AA (1995) The sociolinguistic patterns of native Arabic speakers: Implications for teaching Arabic as a foreign language. Applied Language Learning 6: 65-87.

Huwari IF, Al-Shboul Y (2015) A study on the perception of Jordanian EFL learners' pragmatic transfer of refusals. Advances in Language and Literary Studies 6(1): 4654.

Hymes, D. (1974). Foundations in sociolinguistics: An ethnographic approach. Philadelphia: University of Pennsylvania Press.

Izadi A, Zilaie F (2015) Refusal strategies in Persian. International Journal of Applied Linguistics 25(2): 246-264.

Jianda L (2007) Developing a pragmatics test for Chinese EFL learners. Language Testing 24(3): 391-415.

Kasper G (2000) Data collection in pragmatics research. In H Spencer-Oetay (Eds.), Culturally speaking: Managing rapport through talk across cultures (pp. 317-341). London, England: Continuum.

Kwon J (2004) Expressing refusals in Korean and in American English. MultilinguaJournal of Cross-Cultural and Interlanguage Communication 23(4): 339-364.

Martínez-Flor A, Usó-Juan E (2006) A comprehensive pedagogical framework to develop pragmatics in the foreign language classroom: The 6Rs approach. Applied Language Learning 16(2): 39-63.

Matsugu S (2014) Developing a pragmatics test for Arabic ESL learners. Arab World English Journal 5(3): 3-14.

Maíz-Arévalo C (2014) "I'm sorry I don't agree with you": Can we teach nonnative students pragmatic competence when expressing disagreement?. Revista Española de Lingüística Aplicada 27(2): 433-453.

Migdadi F, Badarneh MA, Momani K (2010) Divine will and its extensions: Communicative functions of maašaallah in colloquial Jordanian Arabic. Communication Monographs 77(4): 480-499.

Morkus N (2009) The realization of the speech act of refusal in Egyptian Arabic by American learners of Arabic as a foreign language. Unpublished doctoral dissertation. University of South Florida, Tampa, FL, USA.

Mostafa M (2015) A study of compliment responses among male and female Egyptian undergraduate students. Unpublished Master's thesis. American University in Cairo, Cairo, Egypt.

Nelson GL, Al Batal M, El Bakary W (1998) Refusals and communication style in American English and Egyptian Arabic. Paper presented at the 20th annual conference of the American Association for Applied Linguistics, Seattle, WA, March 14-17.

Nelson GL, Al Batal M, El Bakary W (2002). Directness vs. indirectness: Egyptian Arabic and US English communication style. International Journal of Intercultural Relations 26(1): 39-57.

Scollon R, Scollon SW (2001) Discourse and intercultural communication. In D Schiffrin, D Tannen, HE Hamilton (Eds.), The handbook of discourse analysis (pp. 538-547). Hoboken, NJ: Blackwell.

Searle J (1969) Speech acts. Cambridge, England: Cambridge University Press.

Shishavan HB (2016) Refusals of invitations and offers in Persian: Genuine or ostensible? Journal of Politeness Research 12(1): 55-93.

Shishavan BH, Sharifian F (2013) Refusal Strategies in L1 and L2: A Study of Persianspeaking learners of English. Multilingua 32(6): 801-836.

Soler EA, Pitarch JG (2010) The effect of instruction on learners' pragmatic awareness: A focus on refusals. International Journal of English Studies 10(1): 65-80. 
Stevens PB (1993) The pragmatics of "No!": Some strategies in English and Arabic. IDEAL 4(6): 87-112.

Thomas J (1983) Cross cultural pragmatic failure. Applied Linguistics 4(2): 91-112.

Usó-Juan E (2013) Effects of metapragmatic instruction on EFL learners' production of refusals. In O Martí-Arnándiz, P Salazar-Campillo (Eds.), Refusals in instructional contexts and beyond (pp. 65-100). New York, NY: Rodopi.

Wolfson N, Manes J (1980) The compliment as a social strategy. Research on Language \& Social Interaction 13(3): 391-410. 


\title{
Appendix A \\ The Discourse Completion Task (DCT)
}

\author{
Consent form
}

Dear Respondent,

The researcher conducting this study under the title of Refusal Strategies among Egyptian Young Adults is for academic purposes related to an M.A. program. You are kindly requested to respond to the following situations as naturally as possible. The data collected from this study will be analyzed collectively and the answers are confidential. You totally have the right not to complete the study or to refrain from answering any of the questions if you like. The whole process of answering the 12 questions will take you less than 20 minutes.

Thank you for volunteering in this research.

Alaa Darwish

Demographic data:

1. Age:

2. Gender:

3. Email or any contact information: ( optional)

4. Have you lived in an English speaking country before? If yes, for how many years?

5. Are you a graduate of public school, national language school or an international one?

Please read the following short scenarios that you could encounter in your daily life. Respond to each scenario with a REFUSAL. Try to make your response as realistic and natural as possible bearing in mind that you are talking to a native speaker of English.

1- You are a junior in college. You attend classes regularly and take good notes. Your classmate who you just met, was sleeping in class and asked you for the lecture notes.

Classmate: Oh God! We have an exam tomorrow but I don't have notes from last week. I am sorry to ask you this, but could you please lend me your notes once again? $(=\mathrm{P},+\mathrm{D})$

To refuse, you say:

2- You arrive home and notice that your cleaning lady is extremely upset. She comes rushing up to you. Cleaning lady: Oh God, I'm so sorry! I had a terrible accident. While I was cleaning, I bumped into the Table and your laptop fell and the screen is broken. I feel very bad about it. I'll pay for it. (-P, +D)

To refuse, you say:

-You teach English Grammar at a university. It is the middle of the semester now and you have finished teaching more than half of the curriculum. One of your students asks to speak to you.

Student: Ah, excuse me, some of the students were talking after class yesterday. We kind of feel that we need more practice in conversation and less on grammar. (- P, -D)

To refuse, you say:

-You are at your cousin's house for lunch. Your cousin offers you Lamb.

Cousin: How about a piece of lamb? I have tried a new recipe; you should try it. (= P, -D)

To refuse, you say:

-Based on your academic performance, your professor offers you a program to study a semester abroad. However, it has to be this summer in which you've already paid for a trip around Europe with your friends. You don't want to miss the fun. Today, your professor calls you into his office. Professor: I'd like to offer you a scholarship to study for a semester abroad this summer. It's a great opportunity in which you will be able to proceed with your studies for 3 months before the next academic year starts. $(+\mathrm{P},+\mathrm{D})$

To refuse, you say:

--It has been a very stressful day and this was your last tutorial. You feel tired 
and you are happy the class will finish in 5 minutes. Your professor asks you to stay for a little longer to discuss the feedback on your previous presentation.

Professor: If it's okay with you, I'd like you to spend an extra 20 minutes so that we can finish discussing the feedback before next week presentation. Can you stay a little longer? $(+\mathrm{P},+\mathrm{D})$

You:

For the Arabic situations please turn the page. 
الأمثلة التالية هي مو اقف إجتماعية من المكن أن تتعرض لها في حياتلك اليومية. رجاءاً اجب بالرفض على كلب من المو اقف الآتية

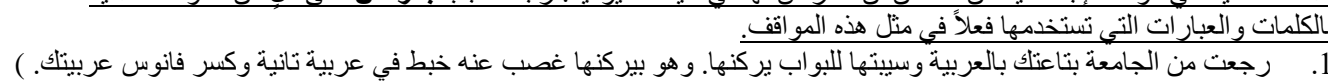
$-\mathrm{P},+\mathrm{D})$

البواب:معلش يا بيد/آنسة و انا بركن العربية غصب عني خبطت في العامود فالفانوس اتكسر بس انا هصلحه على حسابي.

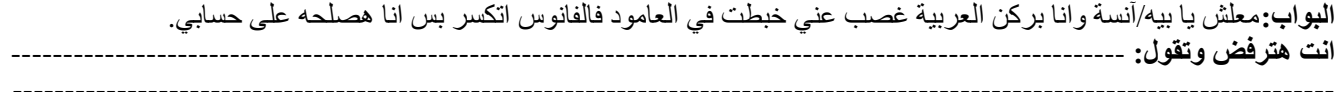

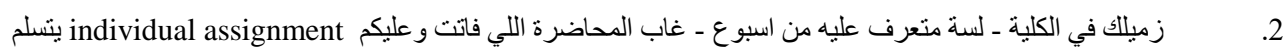

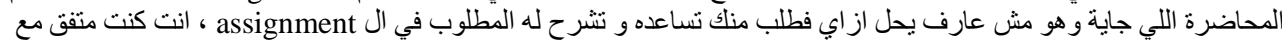

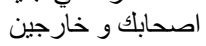

زميلك: هو انت ممكن تجيلي البيت و تساعدني في حل الـ assignment اللي المفروض نسلمه المحاضرة اللي جاية عشان انا كنت غايب

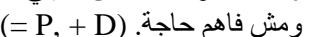
انت هترفض وتقول:

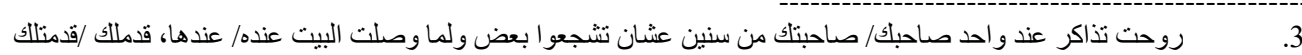
بسكوت بالقرفة مع الثناى. صاحبك/ صاحبتك: لازم تدوق البسكوت ده تحفة ، انا بعمل اوردر مخصوص بيه. (= P, +D) انت هترفض وتقول:

4. الدكتور بتاعك في الجامعة اللي بتشتغل معاه في البحث طلب منك تساعده النهاردة في survey تكتبو ا على الكمبيوتر

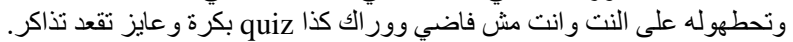

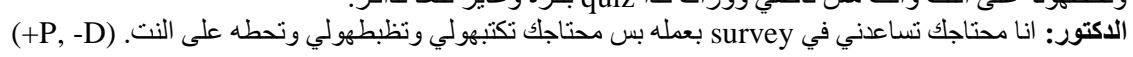

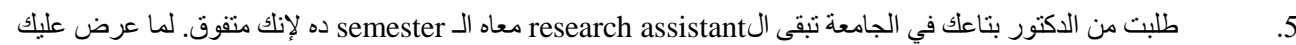

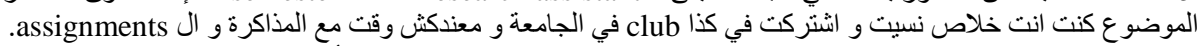

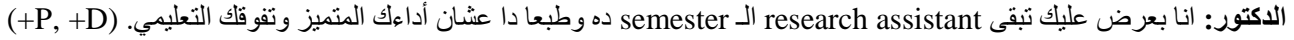

انت هترفض وتقول:

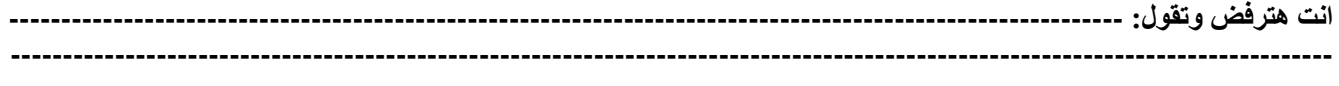

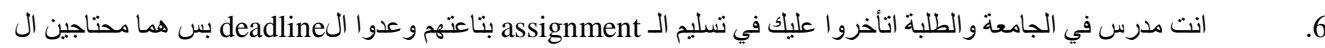
feedback

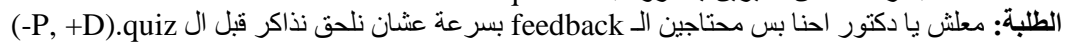




\section{Appendix B}

The Taxonomy of Refusals Adapted from Beebe et al. (1990)

\begin{tabular}{|c|c|c|c|}
\hline $\begin{array}{l}\text { Refusal } \\
\text { Strategy }\end{array}$ & $\begin{array}{l}\text { Sub Categories of } \\
\text { Refusal Strategies }\end{array}$ & Examples & Code \\
\hline \multirow[t]{2}{*}{ Direct } & $\begin{array}{l}\text { Nonperformative } \\
\text { statement }\end{array}$ & Flat "No" & FN \\
\hline & $\begin{array}{l}\text { Negative } \\
\text { willingness/ability }\end{array}$ & "I can’t", "I don’t think so" & Direct \\
\hline \multirow[t]{21}{*}{ Indirect } & $\begin{array}{l}\text { Statement of } \\
\text { regret/Apology }\end{array}$ & "I’m sorry ...", "I feel terrible ..." & Reg \\
\hline & Wish & "I wish I could help you ..." & Wish \\
\hline & $\begin{array}{l}\text { Excuse, reason, } \\
\text { explanation }\end{array}$ & "I have a headache" & Exp \\
\hline & Statement of alternative & "Why don't you ask Ali?" & Alt \\
\hline & $\begin{array}{l}\text { Set conditions for future } \\
\text { or past acceptance }\end{array}$ & $\begin{array}{l}\text { "If you had asked me earlier, I would have } \\
\text {..." }\end{array}$ & Cond \\
\hline & $\begin{array}{l}\text { Promise of future } \\
\text { acceptance }\end{array}$ & "I'll do it next time", "I promise I'll ..." & Promise \\
\hline & Statement of principle & "I never do business with friends" & Principle \\
\hline & Statement of philosophy & $\begin{array}{l}\text { "One can't be too careful", "forgive and } \\
\text { forget" }\end{array}$ & Philo \\
\hline & $\begin{array}{l}\text { Criticize the request/ } \\
\text { insult/attack }\end{array}$ & "That's a terrible idea!" & Crit \\
\hline & $\begin{array}{l}\text { Request for help or } \\
\text { empathy }\end{array}$ & $\begin{array}{l}\text { "I didn't take notes myself, let's find } \\
\text { somebody who can lend us both his notes" }\end{array}$ & RH \\
\hline & $\begin{array}{l}\text { Let interlocutor off the } \\
\text { hook }\end{array}$ & "Don’t worry about it" & Hook \\
\hline & Self-defense & $\begin{array}{l}\text { "I'm trying my best", "I'm doing all I can } \\
\text { do" }\end{array}$ & SD \\
\hline & $\begin{array}{l}\text { Unspecific or indefinite } \\
\text { reply }\end{array}$ & & IR \\
\hline & Silence & & Silence \\
\hline & Physical departure & & PHD \\
\hline & Topic switch & & TS \\
\hline & Joke & "I'm not on good terms with lamb" & Joke \\
\hline & $\begin{array}{l}\text { Repetition of part of } \\
\text { request }\end{array}$ & "Monday?" & Rep \\
\hline & Postponement & "I'll think about it" & Pstp \\
\hline & Hedging & "Gee, I don't know", "I'm not sure" & Hedge \\
\hline & Non-commitment & "I'll try, but I don’t promise anything" & $\mathrm{NC}$ \\
\hline \multirow{4}{*}{$\begin{array}{l}\text { Adjuncts } \\
\text { to } \\
\text { refusals }\end{array}$} & $\begin{array}{l}\text { Statement of positive } \\
\text { opinion }\end{array}$ & "That's a good idea ...", "I'd love to ..." & $\mathrm{PO}$ \\
\hline & Statement of empathy & "I realize you are in a difficult situation" & Emp. \\
\hline & Pause fillers & "Mmmmm", "well", "oh", "uhm" & Filler \\
\hline & Gratitude/appreciation & "Thank you" & Grat \\
\hline
\end{tabular}

